\title{
Comparative Analysis of the Father-Son Relationships in Crystal Boys and The Wedding Banquet
}

\author{
Hailing Sun \\ College of Literature and Journalism \\ Sichuan University \\ Chengdu, China
}

\begin{abstract}
This essay intends to focus on pure and mere familial father-son relationship to trace traditional Chinese family patterns and discuss the new trend of father-son relationship. In accordance with the three themes " $f u$ ci $z i$ xiao", "patricide" and "re-identification", this essay explores three stages of harmony, conflict, and introspection to analyse, compare, and critique the track of father-son relationships in Bai Xianyong's novel Crystal Boys (1983) and Li An's film The Wedding Banquet (1993).
\end{abstract}

Keywords-father-son relationships; fu ci zi xiao; patricide; re-identification

\section{INTRODUCTION}

This essay aims to analyse and compare the representation, construction, and connotation of the fatherson relationships explored in Bai Xianyong's novel Crystal Boys (1983) and Li An's film The Wedding Banquet (1993). As the first and crucial contemporary Chinese works about homosexuality, both are committed to expressing homosexual identity confusion, and solution for social and family conflicts by concentrating on the relationship between father and son. While both works come from Taiwan, the most tolerant and liberal of all Chinese-speaking societies in terms of homosexuality (Song 2006, p.33), they finally move toward different direction after providing a similar insight into the father-son relationship. It is the different ending that makes it meaningful to compare and discuss them for a better understanding of Chinese father-son relationship on homosexual condition and construction.

In the Confucian construct, the family is perceived as the most fundamental and profound of social institutions, and the father-son relationship is at the core of family ethics (Zhou 2000, p.253). The harmony, obedience, conflict, rupture, and compromise presented in father-son relationships precisely reflects the process of migration, communication, change, and creation in the pattern of human culture, as well as reveals the process of discovery, identification, and establishment for freedom, individuality, and dignity. For this reason, analyses of the father-son relationship play a positive role in re-constructing ethic relationships and remolding moral sentiments.
There has previously been abundant but separate research of father-son relationships in Crystal Boys and The Wedding Banquet: Cai Yuanhuang and Long Yingtai analyse the former work based on traditional familism, while Zhang Xiaohong, Ye Dexuan, and Zhu Weicheng discuss it from a "queer" theory perspective. In respect of The Wedding Banquet, most scholars, such as Ma Shengmei, Chris Berry, and Song Huilin, pay attention to Confucian family ethics and a Chinese-Western conflict of values. Because of Taiwan's particular political and historical background, father-son relationships in Taiwanese works usually play a metaphorical role for "family and country" (the lost relation of China). However, under the influence of social change, including metropolitanisation as well as East-West cultural conflict, traditional father-son relationships are viewed in new crisis and introspection.

Based on this consideration, distinguished from the " $f u z i$ jia guo" (father and son, family and country) direction put forward by Mei Jialing and other scholars, this essay intends to focus on pure and mere familial father-son relationships to trace traditional Chinese family patterns and discuss the new trend of father-son relationships. In accordance with "fu ci zi xiao", "patricide" and "re-identification" three themes, this essay will explore three stages of harmony, conflict, and introspection to analyse, compare, and critique the track of father-son relationships in Crystal Boys and The Wedding Banquet.

\section{HARMONY OF "FU CI ZI XIAO": EXPECTATIONS AND OBEDIENCE}

Chinese society, on the basis of Confucianism, has gradually constructed a family structure centered on "patriarchy" and "father-son relationships". Patriarchy means that "fathers have unassailable dominion in the family. They are the property owners and leaders of other family members" (Xu 1992, p.43). The supremacy of the patriarchal system determines that the only mode of the father-son relationship in traditional ethics is "fu ci zi xiao" (piety and kindness). When first mentioned in Li Ji (The Book of Rites), it indicates that the father should be affectionate, and the son should be dutiful. However, according to Li Zehou, this social morality aims to maintain social stability, existence, 
and continuation ( $\mathrm{Li} 1998, \mathrm{p} .31$ ). In the circumstances, it gradually places emphasis on the son's filial piety and obedience rather than the father's love and kindness. As Lu Xun says, "paternal authority is considered absolute: of course whatever the old man says is right, while the son is wrong before he opens his mouth" (Lu 1964, p.53). This unbalanced relationship has existed in China for thousands of years, which influences all aspects of the individual and society, and, thus, has the significance and necessity to be discussed first in the analysis of the father-son relationships in Crystal Boys and The Wedding Banquet. In addition, it must be emphasized that the "father" the author would like to analyse in the following essay refers mainly to the biological father, which can also be comprehended as "phallus father". According to David Macey, Freud uses the notion of "phallus" as "a representation of the erect male organ and a symbol of sovereign power" (Macey 1992, p.318), which can help us understand and discuss the texts and father-son relationships better.

In Crystal Boys, most fathers and sons once had harmonious relationships and even "fu ci zi xiao" (except for some characters' fathers' innate absence, for example, Wang Xiaoyu's) before the discovery of the sons' or the father's homosexual acts. On the one hand, fathers are loving, affectionate, and have great hopes for their sons - although sometimes these expectations are not the sons' own needs and aspirations. Even Li Qing's father, an irritable and unlucky man, has a soft side to Li Qing and his younger brother Buddy. For instance, as Li Qing says, "he didn't have the money to buy decent food for our New Year's dinner [...] Father handed one of the crispy drumsticks to me and the other to Buddy, while he ate the neck along with his wine" (Bai 1990, p.167). Based on this detail, it is plain to see that father's concern may be silent but is never absent. Similarly, $\mathrm{Fu}$ Chongshan teaches his son a military treatise by Zhuge Liang and how to ride and hunt and buys him a decent Omega watch to wear and so on. All of these actions and attitudes indicate that fathers are at loving. Moreover, most fathers have great expectations on their sons, such as $\mathrm{Li}$ Qing's father: "his cherished dream was that upon graduation I would enter the Army's Phoenix Mountain Military Academy to continue in his footsteps" (Bai 1990, p.49). However, the author would argue that this great expectation is not based upon Li Qing's own desire to be a respected officer, it depends on his father's lifelong dream to be able to "wash away the shame of his being captured by the enemy and discharged for army" (Bai 1990, p.177). In the traditional Chinese three cardinal guides (san gang), fathers guide sons; and sons obey fathers' instructions and aspirations. For this reason, the starting point of this kind of harmonious father-son relationship is the father's own desires and wishes.

On the other hand, in Crystal Boys, most sons obey their fathers' instructions and have both emotional attachment and reverence for them. Fu Wei is always with his father $\mathrm{Fu}$ Chongshan, except in battle; he obeys his father's teaching and becomes an outstanding military officer. As such, Fu Chongshan says, "you don't know how pleased that made me. My son had brought me honor" (Bai 1990, p.259). It is the sons' attachment and meeting of expectations that makes fathers desirable to their sons. However, sometimes sons are afraid of their fathers' control. Take Buddy, for example: after waking up Father, Buddy "quickly wrapped his arms around his head and made himself as small as he could" (Bai 1990, p.40). In my opinion, it is Buddy's submission and reverence that makes the father laugh and allows Buddy exemption from punishment. Only a son who reveres his father can he achieve his father's expectations, wishes, and desires. Thus, it can be seen that patriarchal supremacy and filial obedience throughout the growing process of sons.

Similarly, in The Wedding Banquet, father is authoritative and willing to preach; his son always obeys his requirements, overtly agreeing at least, but covertly opposing them. For the father, General Gao, he has sovereign authority in the father-son relationship, as well over the whole family. Although father does not appear until 23 minutes into the film, in his previous absence it is obvious to perceive father's authority by mother's cassette, telephone, blind date arrangement throughout time and space. On camera, father is largely in a narrative background situation, but he controls and advances all the narration. In order to show patriarchy, on the wedding day, father preaches a lot and makes $\mathrm{Gu}$ Weiwei, the bride, cry; thus, he thinks his speech is really impressive and takes pride in it. In addition, it is interesting to notice that when Gao Weitong, the son goes for a walk with his father, General Gao - chest jutted forward - strides confidently and vigorously in front of his son; whereas Gao Weitong, head slightly bowed, walks behind his father. This detail vividly demonstrates father's authority and patriarchy's supremacy in mise-en-scene. Besides, General Gao's greatest expectation for Weitong is to have a grandson to carry on the family line, which is opposed to his homosexual son's own desires. This apart, General Gao loves Weitong dearly. For instance, on the morning of wedding banquet, General Gao reminisces about Weitong's childhood, when he used to love to sleep on father's tummy, and says "stay a bit, we won't probably get another chance", which shows father's love and affection obviously.

Besides, for son, Gao Weitong is at least seemingly filial and obedient. When writing the questionnaire from his parents, although Weitong knows it is stupid to lie, he does not resist and can only say "but I'm used to it". After learning his parents are coming to arrange the wedding, Weitong changes his house style from Western to traditional Chinese style, switching the homoerotic nude photo to his highschool military uniform photo, the western oil painting to his father's calligraphy work, and even lies to his father, saying, "it (father's calligraphy work) is my favorite, that's why it's in the living room". For the sake of representing the reverence and obedience of his father, Weitong comes to be a hypocrite. In traditional Chinese culture, fathers always educate sons based on their own standards. As Li Zehou states, "on the one hand, children, therefore, are obedient, submissive, following rules and respecting authority, on the other hand, they are escaping, cheating and hypocritical" (Li 1987, p.263). However, to some extent, sons' concealment of homosexuality is one kind of representation of filial piety, since, as Weitong says, "I couldn't burden you with what has 
been with me so long". Weitong knows he cannot tell his father the truth because it would kill him, which reflects his filial piety to his father and identity to the "fu ci zi xiao".

According to the analysis above, based on the traditional Chinese ethic of "fu ci zi xiao", both fathers in Crystal Boys and The Wedding Banquet are authoritative and have an affectionate side; as well as great hopes for their sons, although sometimes these expectations are not their sons' own. As Marseille indicates, "father usually be an educator, executor of discipline" (Marseille 1998, p. 254). Most fathers in Crystal Boys and The Wedding Banquet are military officers in Taiwan from mainland China, who are the mighty and normative representatives of traditional Chinese patriarchy - models and symbols of Confucianism ethics. They require sons' total obedience and have high expectations for them, which represents the orders and regulations of family and society. In fact, their expectations are based on "xiao" (likeness). As Mei Jialing argues, "xiao" (likeness) is the core element of "xiao" (filiality); it starts with similar looks and ends with following in the father's footsteps, aiming to continue in both consanguinity and culture (Mei 2012, p.18). In this way, the two most important things for fathers are blood continuity and their aspiration inheritance. As for sons, they should obey fathers' instructions and have both emotional attachment and reverence to their fathers.

Nevertheless, the author would like to argue that the duration of this "fu ci zi xiao" is different in Crystal Boys and The Wedding Banquet. When faced with fathers' desires and hopes, although most sons in Crystal Boys and The Wedding Banquet are homosexuals, they have different attitudes and actions. Most sons in Crystal Boys do not fulfill fathers' expectations: some of them are excellent in aspiration inheritance but cannot have a son to carry on the family name, like Fu Wei; some of them drop out or are dismissed from school, like Li Qing; some of them even die before the fathers, like Buddy. Although they have an attachment to their fathers, they finally disobey their expectations for them and even shatter their fathers' own dreams. As for homosexual fathers like Lin Maoxiong, he also loses his son's respect after being caught of homosexual behaviour. In this way, the author suggests that "fu ci zi xiao" in Crystal Boys only exists before the discovery of fathers' or sons' homosexuality; after that, this harmonious father-son relationship totally vanishes. This is different from The Wedding Banquet. In The Wedding Banquet, it is precisely because Gao Weitong has not been living with his father for ten years and has good grades and work in America and finally has a baby, who is at least ostensibly filial and obedient to his father and traditional ethnics. In the circumstances, "fu ci zi xiao" is maintained and the traditional Confucian ethics continue throughout the story.

\section{CONFLICT OF "PATRICIDE": EXILE AND ESCAPE}

Although this harmonious father-son relationship exists, conflict and strife are the main themes of father-son relationships in Crystal Boys and The Wedding Banquet, as well as in human history. As Freud demonstrates, the struggle between father and son is a constant phenomenon, and the continuity of human society is based on it $\mathrm{CH} 2012$, p.19). For this reason, it is necessary to discuss this kind of father-son relationship in depth. According to Freud's The Interpretation of Dreams and Totem and Taboo, the son has rebellious force to the father's authority and the threat of castration, and query for father's status and patricide action are actually part of the process of constructing the son's own identity and discourse. In Crystal Boys and The Wedding Banquet, the forms of the "patricide" are mainly represented as resistance, exile, escape, and profanation.

In Crystal Boys, conflict and "patricide" represent primarily as exile and banishment in the father-son relationship and it is interesting to notice that the exiled can be both fathers and sons. On the one hand, as adolescent homosexuals, sons are on the margins of society and exiled by both their fathers and the wider community. There are three typical outcast characters who are exiled by their "phallus fathers": namely, Li Qing, forced into prostitution after being thrown out of the family home; Wang Kuilong, forbidden to return to Taiwan until his father's death; and $\mathrm{Fu}$ Wei, who commits suicide after learning of his father's rejection of their meeting. Apart from fathers' punishments, Li Qing's school expulsion, police officer's attitude toward homosexual sons and the news "Wandering into a Den of Fairies" all reflect the exile from the whole society:

Fairies

Fairies

Fairies

Fairies

Fairies

(Bai 1990, p.285)

Here it is plain to see that Bai Xianyong adopts the wry and circulatory typesetting to deepen the hurt of this pejorative in order to show better the public's attitudes. Through these two exiles, sons are castrated by both fathers and society. One the other hand, some fathers are also desecrated, profaned, usurped and exiled by their sons. Take Lin Maoxiong, for example: after being caught taking a boy out of a bar, his son raises such an outcry and Lin Maoxiong does not know what to do. In fact, "this was just the chance the kid was waiting for to take over some of the family concerns" (Bai 1990, p.131). Here, the son not only portrays the father to be the morally corrupt, but also challenges the patriarchy and usurps power, which is supported by the power of social criticism.

For this reason, the author would argue that the conflicts between fathers and sons in Crystal Boys represent conflicts between individual and society; heterosexual fathers' attitudes towards homosexual sons, or heterosexual sons' attitudes towards homosexual fathers are substantially social attitudes towards homosexuality. Some scholars, for example, Cai Yuanhuang, indicate that fathers' attitudes towards sons are social attitudes towards homosexuality. However, although Bai Xianyong also says "fathers represent an attitude of Chinese society, an attitude towards next generation and homosexual sons and daughters" (Bai 1998, 
p.1), the author suggests that these scholars' expression may be not accurate enough. They may ignore the exiled father character, although it is not as obvious as exiled son character. In my opinion, on the one hand, as discussed before, homosexual sons do not fulfill fathers' expectations both on blood continuity and aspiration inheritance; it is precisely because of social banishment and marginalization that homosexual sons are exiled by their fathers. On the other hand, homosexual fathers also do not play a perfect role in heterosexual sons' expectations. In order to not lose the face of patriarchy, homosexual fathers, the moral corrupted, are desecrated, profaned, usurped and exiled by their sons. Why sons have the power and courage to challenge patriarchy? According to Zheng Tiantian's analysis, during the imperial period of China, "there was no fixed or reified sexual identity linked to a certain sexual preference" (Zheng 2015, p.33), it is in the twentieth century that "the onslaught of Western medical knowledge changed this cultural tradition and indoctrinated in society heteronormativity and a pathologized and vilified vision of homosexuality" (Zheng 2015, p.33), hence the homoerotic relationships are "immoral, deviant, decadent, ultimately and the cause of a weak notion" (Zheng 2015 , p.39). It is precisely the power of the society and social attitudes towards homosexuality that give sons the opportunity to control, banish, and "murder" their fathers. In this way, the core of conflicts between fathers and sons are social disagreements towards homosexuality.

In The Wedding Banquet, there are three main conflict plots in the film, namely: (1) homosexuality or heterosexuality; (2) hosting the wedding banquet or not, and (3) having a grandson or exercising foeticide. Of these three conflicts, the decision concerning whether to have a grandson or not is the core conflict. As Mencius says: "of the three unfilial acts, to have no son is the worst" (Mencius 2001, p.339). Because all of the Gao family in mainland China is dead during the battle, what General Gao concentrates on is having a grandson to carry on his family name. Remarking on the size of Weiwei's pelvis, General Gao comments that, "she'll make a lot of babies". This directly reveals General Gao's desire for a grandson. Another detail which reflects General Gao's craving for a grandchild is that when he suffers the stroke in the ambulance, it is the wish to hold his grandchild that make him cling to life. For this reason, the father, General Gao's expectation of blood continuity and the son, Weitong's homosexuality bring them into conflict. In the film, Weitong's ways of resolve this conflict are to escape and avoid the problem. For specific performance, Weitong lies and cheats to his father through changing his house style and making the fake marriage. Under the pressure of patriarchy, he has no courage to resist or rupture the father-son relationship; he can only avoid the conflict and maintain the superficial harmony. When this conflict cannot be concealed any longer, especially when $\mathrm{Gu}$ Weiwei is pregnant unexpectedly, Weitong is forced to move towards "patricide" - namely, induced abortion.

For my part, these conflicts in The Wedding Banquet reflect Chinese-Western intergenerational and marital ethics conflicts. Under the control of patriarchy, the core of Chinese family is the father, and the individual interest shall subject to the family interest. By contrast, in Western society, the core of family is the couple, and individual interest is the basis of choice. Same as homosexuals, Simon, Weitong's gay lover, has told his parents about his homosexuality. However, Weitong cannot violate his father's expectation. As Fran Martin expresses, this "stages a kind of postcolonial cultural clash between two regimes of sexuality: broadly, a 'Chinesefamilial' regime, and a regime of 'American gay identity' (Martin 2003, p.143)" Moreover, the comparison between the complicated Chinese wedding ceremony and the simple Western wedding is also a representation of this conflict. When the Americans cannot understand why the wedding banquet is so tedious, $\mathrm{Li} \mathrm{An}$, being a guest performer, indicates the root: "you are witnessing the result of five thousand years of sexual repression", which reflects the theme of this film: situating it at the crossroads of "nationalist patriarchy and gendered minoritisation" (Shi 2000, p.90).

In comparing Crystal Boys and The Wedding Banquet, it is plain to see that their conflicts come from the same root: suppression of discourse for sons. Patriarchs always control their sons' lifestyle and value; as Li Yiming argues, "in terms of sociology, they are external rulers who are focused by younger generation's ambivalent feelings; in terms of psychology, they become the impassable inner obstacle for the psychological development of the younger generation" (Li 1989, p.10). In these circumstances, sons pursue independent personality, power, and change of social order, "through 'patricide', [...] break away from a group of aphasic state, resist the will to power and battle for discourse" (Sheng 1997, p.69).

Moreover, the author would argue that there are two main differentiae to the father-son conflict in Crystal Boys and The Wedding Banquet. Firstly, according to previous analysis, the struggle between fathers and sons in Crystal Boys represent a virtual conflict between society and the individual, while that in The Wedding Banquet reflects the clash of Chinese-Western intergenerational and marital ethics. Secondly, the conflicts in these two stories vary in their extent. In Crystal Boys, the bonds between fathers and sons are broken irrevocably by exile, banishment, and death, while in The Wedding Banquet, General Gao, and Weitong avoid conflicts by lying, and thereby sustain superficial harmony in their father-son relationship. The reason for this is that, in Crystal Boys, fathers are powerful and strong, and they have absolute authority over their adolescent or young sons. However, in The Wedding Banquet, the father is old, weak, and ill, and the son is middle-aged, successful, and independent. Thus, the conflict between strong fathers and their sons results in rupture, whereas, by contrast, through traditional warm moving and inspiration, weak fathers make the "patricide" of their sons difficult and guilt-ridden, which reflects both irreversible decline and fall of old patriarchy and sympathy for the culture that fathers represent.

\section{INTROSPECTION OF "RE-IDENTIFICATION": SEARCH AND COMPROMISE}

After conflict and various forms of "patricide", father-son relationships in Crystal Boys and The Wedding Banquet turn 
in a new direction. It is significant to analyse the attitudes, psychology, and behaviors of fathers and sons in order to explore their new relationship and perceive the connotation of these two works deeply. According to theories about Freud's "Oedipus complex" and Lacan's "Mirror Stage", after conflict and "patricide", sons grow up and move beyond this stage to internalize "the name of the father" and "the law of the father" consciously, and review and obtain their reidentification to their fathers (Feldstein 1996, p.133). However, because of specific differentiations, sons in Crystal Boys and The Wedding Banquet take different approaches to introspection and re-identification. Some construct new patriarchy and their own discourse, some achieve a compromise with their fathers and return to the original ideology, whereas others, who can bear neither the burden of constructing a new discourse or accepting the old patriarchy, are driven to self-exile on the margins of society.

As Bai Xianyong states, "Crystal Boys can be regarded as a note of finding father [...] in order to reconstruct their homes, they find their fathers as well as themselves" (Bai 2000, p.548). Here, the father can be both the biological father (the "phallus father") as well as the spiritual father. For the former, sons have mixed feelings: Li Qing, although he knows he has to keep away from his father because he "couldn't bear to see the look of anguish on his devastated face" (Bai 1990, p.265), however, through belittling himself ("occasionally I wondered if he still held out a thread of hope that I might reject my sinful past and come home to start anew" ( Bai 1990, p.177), he turns towards "self-castration" by the value system of "the name of the father"; whereas Wang Xiaoyu, different from the escape and fear of Li Qing or Wang Kuilong, he searches for his biological father actively: "I won't rest, dead or alive, until I've found that goddamn father of mine!" (Bai 1990, p.131). In fact, his purpose for finding father is actually finding his roots and self-identity, as he says he will "be content just knowing that he exists" (Bai 1990 p.131). Unfortunately, all their searches for their biological fathers fail because of various factors. For this reason, original family structures deconstruct because sons have "murdered" or "lose" their biological fathers, and they also do not want to be the father. The sons revolt against the old social order; however, after the destruction of old values, they cannot construct a new value system. Under these circumstances, the younger generations can only exile themselves on the margin of society and search for their spiritual fathers.

There are three different kinds of spiritual father in Crystal Boys: the first are "hedonistic fathers" or "fathers of enjoyment"; in other words, homosexual boys' companions, such as Chief Yang, Grandpa Guo, and Lord Sheng, who are nostalgic or sad for lost youth and beauty; the second are "anal fathers", indecent men with strong carnal desire like Lao Zhou and Boss Wu; the third are good-hearted people who sympathize with homosexual boys in their misfortune, like Fu Chongshan. According to the analysis of Zhang Xiaohong, "the (homosexual) desire is expressed in the form of a pseudo-father-son relationship. This interaction between adoptive fathers and sons, male patrons and hustlers, thus establishes a subcultural pseudo-kinship network". (Zhang
1998, p.170) However, the author would argue these pseudoanal fathers cannot help homosexual sons to construct a new home and discourse. Take Xiaoyu for example; as Michel Foucault indicates, sexual behaviours between older men and younger boys are usually preceded in games of escaping, rejecting, and dodging (Foucault 1990, p.397). Thus, Wang Xiaoyu escapes from Old Zhou to Boss $\mathrm{Wu}$, and from Boss Wu to Lin Maoxiong but never succeeds in constructing his new home and discourse because he has perceived "the love from anal father is false and illusory, it is exchange of money for sex acts, it is a kind of (homosexual) desire" (Zhu 2001, p.109). Furthermore, Fu Chongshan, the virtual spiritual father, is the tie of two generations and the link between homosexual sons and the orthodox society. On the one hand, after Fu Wei (Fu Chongshan's homosexual son)'s suicide and meeting with A-feng, Fu Chongshan promises himself that he will extend a helping hand to park kids who live such uncertain lives; on the other hand, he reveals the biological father's true suffering by telling Wang Kuilong that "no matter how great your agony, his (Wang Kuilong's father Wang Shangde's) was greater" (Bai 1990, p.257). Moreover, through living together, Fu Chongshan, the "normal" father, and Li Qing, the "freak" son, start a new trans-border family. According to the plot of Fu Chongshan's funeral, as Zeng Xiuping argues, it is precisely through various funeral ceremonies that make homosexual sons - who are eager for filial piety and salvation - obtain dignity and approval as sons of man (Zeng 2003, p.258). In this way, these "freak" sons are transformed from "crystal sons" to "sons of man" and achieve salvation, and make a construction of their reidentification.

By contrast, faced with conflicts, father and son in The Wedding Banquet turn toward compromise. Chris Berry contextualizes the film in the genre of the family melodrama that promotes "audience empathy and identification [...] with the Confucian family unit as it negotiates the interface with globally hegemonic American culture" (Berry 2003, p.183). Based on his argument, the author would analyse that reason why they can arrive at a compromise is an interactional result of the father and son's comprehension, concession, and deep love. For General Gao, the objective condition for his compromise is that Weitong has been married and produced progeny. As Zheng Tiantian expounds, in traditional Chinese culture, "sexuality was believed to be malleable, and variegated sexual behaviors were accepted as long as family responsibilities were fulfilled" (Zheng 2015, p.39). In this way, General Gao's great expectation has been achieved at least. In the subjective aspect, it is precisely General Gao's comprehension and traditional Chinese magnanimous cultural character that promotes his compromise. General Gao, who has also resisted a marriage imposed on him by his father, has to "extend this flexibility to his dealings with his son, for their parallel experiences as rebels would have made it morally difficult for him to reject Weitong's rebellion" (Song 2006, p.64). His thanks to Weiwei and recognition of Simon by the secret hong bao (a red packet) reflect "both an affirmation and a revaluation of Confucian ethics" (Leung 2008, p.31). In this way, in the ambiguous ending of the film, the father raises his arms while being frisked by the security officer. Through the use of slow-motion and soft light, this 
philosophic gesture is not so much a symbol of surrender but really reflects the victory of blood succession (Wei 1997, p.202), as well as traditional Chinese character's extraordinary detachment and magnanimity. In this way, General Gao's posture of apparent failure is actually winning, and he "becomes a successful loser" (Yu 2005, p.115).

As for the son in The Wedding Banquet, although sticking to his homosexuality, Weitong's compromise reflects his re-identification to his father, as well as the traditional Chinese culture that General Gao represents. In this film, the father, a general who is good at calligraphy, is a representative of Chinese traditional cultural essence. His speech and deportment, attitudes, and self-control, all influence Weitong's ways of thinking and doing things. As stated, "in Chinese culture, we try to calm things down, to find harmony. It's always repress, repress, then explode" (Stone 1997, p.597). Weitong cheats and conceals all because this attitude, which reflects his unconscious identity of father's culture. Besides, on the morning of the wedding day, Weitong returns to his father's bosom and accepts his touch, which can also be regarded as a symbol of reidentification to General Gao. Through these plots and details, from conflict to compromise, Weitong completes his introspection and obtains re-identity.

According to the previous analysis, both Bai Xianyong and $\mathrm{Li}$ An pay close attention to the new direction of the father-son relationship after conflicts or "patricide". Sympathy for sons' identity confusion, the struggle between free will and duty, introspection, as well as comprehension and revaluation of fathers' feelings are reflected in Crystal Boys and The Wedding Banquet. However, their endings finally turn towards different directions: in Crystal Boys for search and The Wedding Banquet for compromise. For those freak boys in Crystal Boys, "the process of 'finding father' means the process of finding social inclusion" (Yang 2013, p.54). Neither bear the burden of constructing new discourse or accept the old patriarchy, freak boys can only go into selfexile on the margins of society. In Crystal Boys, the original family structures are deconstructed, but freak sons cannot construct new value system. In the process of searching for their spiritual fathers, "hedonistic fathers" and "anal fathers" cannot help them reconstruct themselves, and only transborder spiritual father, Fu Chongshan contributes to the sons' salvation and re-identification, from "freak sons" to "sons of man". However, whether constructing a new trans-border family or a freak homosexual family to displace the original family, the "family" is dissimilated, thus freak sons' search is dissimilated and the inner-exile makes them lonely and perplexed. By contrast, faced with conflicts, the father, and son in The Wedding Banquet turn towards compromise. It is an interactional result of the father and son's comprehension, concession, and deep love. Through the moderate selfrenewal development of revaluation, affirmation of Confucian ethics by magnanimous cultural character, and toleration of heterogeneous culture, the father defends traditional Chinese culture and ethics in the multicultural society. On this occasion, finally, The Wedding Banquet both rationalizes younger generations' identification and desires, and affirms traditional identification and the father-son order.

\section{CONCLUSION}

According to the above analysis and comparison of the representation, construction, and connotation of the fatherson relationships, this essay has demonstrated that there are three primary forms of representation of father-son relationships in Crystal Boys and The Wedding Banquet: harmony of " $f u$ ci zi xiao", conflict of "patricide", and introspection of "re-identification". In fact, these three forms of representation actually reflect three stages of process: "attachment - patricide - regress". First, based on the Chinese traditional ethic "fu ci zi xiao", most fathers and sons in Crystal Boys and The Wedding Banquet have affection for each other; the fathers have great hopes for their sons for both blood continuity and aspiration inheritance, although sometimes these expectations are not their sons own needs and aspirations. As for sons, they obey their fathers' instructions and have reverence for them. However, "fu ci zi xiao" in Crystal Boys only exists before the discovery of homosexuality, while in The Wedding Banquet it is maintained, and the traditional Confucian ethics continue throughout the story. Second, the most important father-son relationship, conflict and "patricide" in Crystal Boys and The Wedding Banquet both come from the same root: suppression of discourse. However, the struggle between fathers and sons in Crystal Boys shows a virtual conflict between society and the individual, while that in The Wedding Banquet reflects the clash of Chinese-Western intergenerational and marital ethics. Besides, conflicts in these two stories vary: in Crystal Boys, fathers and sons break irrevocably by exile, banishment, and death, while in The Wedding Banquet, General Gao and Weitong avoid conflicts by lying and thereby sustaining superficial harmony in their father-son relationship. Third, after conflict or "patricide", sympathy for sons' identity confusion, the struggle between free-will and duty and introspection, as well as comprehension of fathers' feeling and revaluation are both reflected in Crystal Boys and The Wedding Banquet. Nevertheless, they finally turn towards different directions of ending: Crystal Boys for dissimilated search and The Wedding Banquet for compromise.

Based on the above discussion, some suggestions can be drawn: on the one hand, for sons, it is significant to rationalize the re-identity to fathers and traditional Chinese virtues; in the meantime, to persist in their own free-will, identification, and discourse to construct their independence. On the other hand, for fathers, as Lu Xun says, "since they (sons) are separate from us, they should be emancipated at the same time so that they belong entirely to themselves and become independent" (Lu 1964, p.62). Through moderate self-renewal development of ethical revaluation, full respect to individual and toleration of heterogeneous culture, fathers are able to perfect magnanimous personality and defend traditional culture and ethics in today's multicultural society. In this way, fathers and sons can construct a kind of balanced and positive relationship, and promote social development as well as human progress. 
[28] Yu Qunfang, "The Electra Complex of Li An's Movies". Contemporary Film, 4 (2005), pp. 115-117

[29] Yang Yifan, "Analysis of the Father-son Relationships in Crystal Boys". Qingnian Litterateur, 6 (2013), pp. 45

[30] Zeng Xiuping, Lonely Official.Crystal Boys.Taibei People: Analysis of Bai Xianyong's homosexual novels. Taibei: Erya Publishing House, 2003

[31] Zhang Kerong, ed, Chinese Overrun the Whole World: Li An. Beijing: Modern Publishing House, 2005

[32] Zhang Xiaohong, "The Unfilial Monstrous Literary History: the Example of Crystal Boys". Comprehensive Discussion of the History of Taiwan Modern Noverl, ed. by Chen Yizhi. Taibei: Lianjing Publishing House, 1998

[33] Zheng Tiantian, Tongzi Living - Men Attracted to Men in Postsocialist China. Minneapolis: University of Minnesota Press, 2015

[34] Zhou Huashan. Tongzhi: Politics of Same-Sex Eroticism in Chinese Societies. New York: Haworth, 2000

[35] Zhu Weicheng, "Father China-Mother (Monstrous) Taiwan? Bai Xianyong's Family Romance and National Imaginations". Chinese and Foreign Literature, 7 (2001), pp.107-111

[9] Freud, Sigmund, Totem and taboo: resemblances between the psychic lives of savages and neurotics. Middlesex: Penguin Books, 1938

[10] Hu Weiyao, "Father-son Theme in Chinese Films", Film Literature, 8 (2012), pp. 18-20

[11] Leung William, "So Queer Yet So Straight: Ang Lee's The Wedding Banquet and Brokeback Mountain", Journal of Film and Video, 60 (2008), pp. 23-42

[12] Li Yiming, "After Patricide : Families in Contemporary Films: Loss and Compensation", Film Art, 6 (1989),pp.9-18

[13] Li Zehou, Reading the Analects Today. Hefei: Anhui Literature and Art Publishing House, 1998

[14] Li Zehou, Modern Chinese Ideological History. Beijing: China Eastern Press, 1987

[15] Lu Xun, "What is required of us fathers today", Selected Works of Lu Hsun, trans. Hsien-yi Yang and Gladys Yang, 2 Vol. Beijing: Foreign Languages Press, 1964

[16] Macey, David, "Phallus: Definitions", Feminism and Psychoanalysis, ed. by Elizabeth Wright. Cambridge: Blackwell, 1992

[17] Marsella, Anthony J., and others, eds, Culture and self: Asian and Western perspectives. New York: Academic Press, 1979

[18] Ma Sheng-mei. "Ang Lees' Domestic Tragicomedy: Immigrant Nostalgia, Exotic/Ethnic Tour, Global Market", Journal of Popular Culture, 30 (1996), pp.19-201

[19] Mei Jialin, "Orphans? Crystal Boys? Wild children? - Father and Son, Home and Country and the Fission in the Taiwanese Novel after the War". Literature and Art Contention, 6 (2012), pp.14-26

[20] Mencius, Mencius. Taibei: New Literature Abundance Publishing House, 2001

[21] Sheng Ning, Cultural Confusion and Introspection: Criticism on Western Postmodernism. Shanghai: SDX Joint Publishing Company, 1997

[22] Shi Shumei, "Globalisation and Minoritisation: Ang Lee and the Politics of Flexibility", New Formations, 40 (2000), pp.86-101

[23] Song Huilin, Celluloid Comrades - Representations of Male Homosexuality in Contemporary Chinese Cinemas. Honolulu: University of Hawai'i Press, 2006

[24] Stone, Judy, "Taiwan: Ang Lee", Conversations With International Filmmakers. Beverly Hills: Silman-James, 1997

[25] The Wedding Banquet, dir. Li An. Good Machine, 1993

[26] Wei Ming Dariotis and Eileen Fung, "Breaking the Soy Sause Jar: Diaspora and Displacement in the Films of Ang Lee", Transnational Chinese Cinemas: Identity, Nationhood, Gender, ed. Sheldon Hsiaopeng. Honolulu: University of Hawai'i Press, 1997

[27] Xu Yangjie, History of the Chinese Family System. Beijing: People's Literature Publishing House, 1992 